\title{
Educação freireana em comunidades quilombolas e implementação do ensino de História na comunidade Manga/Iús no município de Batalha, Piauí
}

Elvis Gomes Marques Filho ${ }^{1}$, Luiz Gustavo da Rocha Moraes ${ }^{2}$, Ingred Dayane Carvalho Macêdo ${ }^{3}$, Francisca Maria Sousa Melo ${ }^{4}$

\begin{abstract}
Resumo
O processo colonizador brasileiro perpetuou uma cultura eurocêntrica, marginalizando grupos não brancos. Esse apagamento resultou no não reconhecimento de indivíduos negros e indígenas como partícipes da sociedade. Por esse motivo, em conquista dos movimentos negros, reconheceu-se a importância da educação quilombola nas escolas públicas e privadas brasileiras, a fim de perpetuar a história e cultura afro-brasileira e indígena. Todavia, esse ensino ainda é precário, haja vista o racismo estrutural brasileiro. Esse texto busca mostrar a eficácia da aplicação da Lei $n^{\circ} 10.639 / 2003$ em uma escola presente na comunidade quilombola remanescente Manga-Iús, localizada no município de Batalha, Piauí. Para a pesquisa foi realizada uma pesquisa bibliográfica e de campo, de caráter qualitativo, fundamentada nas ideias de Paulo Freire, levando em consideração seus pensamentos, e entrevistas do presidente da comunidade e do professor de história da escola pesquisada.
\end{abstract}

\section{Palavras-chave}

Educação quilombola. Ensino de História. Dificuldades de implementação. Leis educacionais.

\footnotetext{
${ }^{1}$ Mestrando em Direito (Direitos Humanos) na Universidade Federal de Mato Grosso do Sul, Brasil; professor efetivo da Universidade Estadual do Piauí, Brasil; líder do Grupo de Estudo, Pesquisa e Extensão Esperança Garcia (GEPEG/UESPI/CNPq); membro do Núcleo Docente Estruturante do Curso de Direito (UESPI). Email: elvisfilho@pcs.uespi.br.

${ }^{2}$ Graduando em História na Universidade Estadual do Maranhão, Brasil; membro do Grupo de Estudo, Pesquisa e Extensão Esperança Garcia (GEPEG/UESPI/CNPq). E-mail: lgustavomoraes8@ outlook.com.

${ }^{3}$ Graduanda em Direito na Universidade Estadual do Piauí, Brasil; membro do Grupo de Estudo, Pesquisa e Extensão Esperança Garcia (GEPEG/UESPI/CNPq). E-mail: ingredayane@ gmail.com.

${ }^{4}$ Especialista em História do Brasil pela Universidade Estadual Vale do Acaraú, Ceará, Brasil; membro do Grupo de Estudo, Pesquisa e Extensão Esperança Garcia (GEPEG/UESPI/CNPq); professora da rede estadual de educação do Piauí, Brasil. E-mail: franciscamelolu@gmail.com.
} 


\title{
Freirean education in quilombola communities and implementation of History teaching in the Manga/Iús community in the municipality of Batalha, State of Piauí, Brazil
}

Elvis Gomes Marques Filho ${ }^{5}$, Luiz Gustavo da Rocha Moraes ${ }^{6}$, Ingred Dayane Carvalho Macêdo ${ }^{7}$, Francisca Maria Sousa Melo ${ }^{8}$

\begin{abstract}
The Brazilian colonizing process perpetuated a Eurocentric culture, making non-white groups invisible. This erasure resulted in the nonrecognition of black and indigenous individuals as participants in society. For this reason, due to the achievements by the African movements, the importance of Quilombola education in Brazilian public and private schools was recognized, in order to perpetuate Afro-Brazilian and indigenous history and culture. However, this teaching is still precarious in view of the structural racism in Brazil. This text intends to demonstrate the ineffective application of the Law $\mathrm{n}^{\circ} 10.639 / 2003$ in school teaching, presented in the remaining quilombola community Manga-Iús, located in the municipality of Batalha, State of Piauí. For this research, a qualitative bibliographic and field research was carried out, supported by Paulo Freire ideas, taking in consideration his thoughs as well as his interviews with the president of the community and the History teacher of the school in which the research was performed.
\end{abstract}

\section{Keywords}

Quilombola education. History teaching. Implementation difficulties. Educational laws.

\footnotetext{
${ }^{5}$ Master degree student in Law (Human Rights), Federal University of Mato Grosso do Sul, Brazil; full professor at the State University of Piauí, Brazil; leader of the Esperança Garcia Study, Research and Extension Group (GEPEG/UESPI/CNPq); member of the Structuring Faculty of the Law Course (UESPI). E-mail: elvisfilho@pcs.uespi.br.

${ }^{6}$ Undergraduate student in History, State University of Maranhão, Brazil; member of the Esperança Garcia Study, Research and Extension Group (GEPEG/UESPI/CNPq). E-mail: lgustavomoraes8@outlook.com.

${ }^{7}$ Undergraduate student in Law, State University of Piauí, Brazil; member of the Esperança Garcia Study, Research and Extension Group (GEPEG/UESPI/CNPq). E-mail: ingredayane@gmail.com.

${ }^{8}$ Specialist in Brazilian History from the State University of Vale do Acaraú, Ceará, Brazil; member of the Esperança Garcia Study, Research and Extension Group (GEPEG/UESPI/CNPq); teacher at the state education system in Piauí, Brazil. E-mail: franciscamelolu @ gmail.com.
} 


\section{Introdução}

Que cultura é a poesia dos poetas letrados de seu País, como também a poesia de seu cancioneiro popular. Que cultura é toda criação humana. (FREIRE, 1967, p. 109).

O Brasil é um país formado a partir da contribuição de diferentes culturas, entre as quais se destacam as culturas Negra, Indígena e Europeia. Apesar de saber que muitos são os esforços desses diferentes grupos e de várias instituições para que todos os brasileiros possuam os mesmos direitos, são notórias as desigualdades sociais, principalmente no que se refere às populações negras. Diante desse quadro, debates promovidos nos últimos anos têm trazido à tona a questão do ensino em escolas rurais quilombolas remanescentes. Alguns deles constituíram-se diante do fato desses indivíduos considerarem-se ou não remanescentes, ou descendentes, de populações quilombolas.

Os territórios remanescentes de comunidades quilombolas são concretizações advindas das conquistas das comunidades afrodescendentes no Brasil. Fruto das várias e heroicas resistências aos modelos escravagistas e opressores instaurados no Brasil colônia. O quilombo representava uma espécie de núcleo de resistência, podendo surgir em qualquer área onde houvesse escravismo, o que significa que não havia nenhuma característica física ou geográfica que lhes predeterminasse a formação:

\footnotetext{
A palavra Kilomboé originaria da língua banto Umbundo, falada pelo povo Ovimbundo, que se refere a um tipo de instituição sociopolítica militar conhecida na África Central e, mais especificamente, na área formada pela atual República democrática do Congo (antigo Zaire) e Angola. (MUNANGA; GOMES, 2004, p. 71-72).
}

Moura (1987, p. 34) caracteriza que as organizações dos quilombos eram muito variadas, dependendo do espaço ocupado, de sua população inicial, da qualidade do terreno em que se instalavam e das possibilidades de defesa contra as agressões das forças escravistas. Aproveitavam-se desses recursos naturais regionais, e os exploravam ou industrializavam, dando-lhes, porém, uma destinação diferente no setor da distribuição. Ao invés de se centrarem na monocultura que caracterizava a agricultura escravista, que também monopolizava a produção na mão dos senhores, os quilombos praticavam uma economia policultora, ao mesmo tempo, distributiva e comunitária, capaz de satisfazer as necessidades de todos os seus membros. 
Freire (1967) caracteriza a separação entre homem e animais através das suas relações, que extrapolam a necessidade de reprodução. Assim, as relações "que o homem trava no mundo com o mundo (pessoais, impessoais, corpóreas e incorpóreas) apresentam uma ordem tal de características que as distinguem totalmente dos puros contatos, típicos da outra esfera animal" (FREIRE, 1967, p. 39).

A história, os pensamentos, a cultura, são todos mecanismos de autenticação do que é ser o homem e a sua relação com o mundo. A defesa da educação quilombola é primordial para reafirmar o pensamento de Freire, no qual busca compreender os anseios, o papel histórico, o real lugar e a valorização dessa cultura.

Acredita-se que a educação ainda seja a porta de acesso pela qual muitos brasileiros negros serão incluídos na sociedade e poderão usufruir de tudo a que têm direito sem que precisem lutar na justiça por algo que é garantido por lei. Esse cenário de lutas por direitos e igualdade social vem se modificando, em especial nos últimos anos. Ressaltam-se dois momentos fundamentais na história que garantem esse direito a esses povos. O primeiro foi o fato de o Estado brasileiro reconhecer oficialmente as comunidades quilombolas por meio do artigo 68 do Ato das Disposições Constitucionais Transitórias da Constituição (ADCT), em 1988. O segundo momento se deu com a implementação da Lei $n^{\circ} 10.639 / 2003$, que tornou obrigatório o ensino de História e Cultura Afro-Brasileira no currículo escolar brasileiro.

Com base em relatos ${ }^{9}$ do Presidente da comunidade Manga/Iús, Francisco José de Carvalho, a comunidade obteve o reconhecimento por parte da Fundação Palmares em 2005, tendo como base o Decreto de $\mathrm{n}^{\circ} 4.887$, de 20 de novembro de 2003, que regulamentou em todo território nacional os procedimentos para identificação, delimitação, reconhecimento e titulação das terras ocupadas por estas comunidades. Desse modo, as comunidades remanescentes de quilombos tornam-se amparadas pela lei brasileira.

De acordo com o art. $2^{\circ}$ do Decreto $n^{\circ} 4.887 / 2003$, os quilombos são entendidos como "grupos étnico-raciais segundo critérios de auto atribuição, com trajetória histórica própria, dotados de relações territoriais específicas, com presunção de ancestralidade negra relacionada com a resistência à opressão histórica sofrida" (BRASIL, 2003a, p. 4).

É nesse contexto que a comunidade remanescente Manga/Iús emerge, fruto da diáspora africana, ainda pouco conhecida no contexto da sociedade brasileira de maneira geral, e na educação escolar, em específico, daí a inquietação acerca do tema abordado, visto

\footnotetext{
${ }^{9}$ Todos os depoimentos foram coletados mediante autorização, via Termo de Consentimento Livre e Esclarecido (TCLE), para serem utilizados na pesquisa.
} 
que, no âmbito escolar daquela comunidade, assim como nas demais escolas a Lei $\mathrm{n}^{\mathbf{o}}$ $10.639 / 2003^{10}$, ainda é superficial.

Com base em depoimentos do Presidente da Comunidade Manga/Iús, Francisco José de Carvalho, falta interesse dos docentes, quanto à busca por formação continuada, assim como o interesse pelo tema. A fala ${ }^{11}$ do Presidente da Comunidade Manga/Iús esclarece que:

A única escola que há na Comunidade, o poder público tentou desativá-la.
Foram necessárias as mães, juntamente com outras pessoas que moram nas
proximidades, se unirem, fazerem abaixo assinado para que a escola não
fechasse as portas. Após muita reivindicação, finalmente o fato não se
concretizou, a escola permanece funcionando só um turno, mas obedecendo
as grades curriculares comuns, sem priorizar em suas atividades,
conhecimentos pautados dentro de sua cultura específica.

Os quilombos, todavia, não se perderam no passado. Eles se mantêm vivos, na atualidade, por meio da presença ativa das várias comunidades quilombolas existentes nas diferentes regiões do país. O direito a uma educação escolar que respeite e reconheça sua história, memória, tecnologia, territórios e conhecimentos tem sido uma das reivindicações históricas dessas comunidades e das organizações do movimento quilombola.

Sendo o ensino de história uma das principais ferramentas para a disseminação da cultura e compreensão do passado e futuro de um povo, ele deve ser ministrado com respeito e seriedade, sem omissões de fatos ou discriminações por parte dos que o fazem, isso torna ainda mais significativa a aprendizagem. Freire (1967, p. 41) discorre que

Não há historicidade do gato pela incapacidade de emergir do tempo, de discernir e transcender, que o faz afogado num tempo totalmente unidimensional - um hoje constante, de que não tem consciência. O homem existe no tempo. Está dentro. Está fora. Herda. Incorpora. Modifica. Porque não está preso a um tempo reduzido a um hoje permanente que o esmaga, emerge dele. Banha-se nele. Temporaliza-se.

O homem, segundo Freire, utiliza o tempo da melhor forma. Ele não está preso no tempo, por isso, desenvolveu sua história através da convivência, da política, da cultura e da educação. Pensando na importante contribuição dos povos africanos e dos quilombos para a formação do povo brasileiro, e atrelando ao pensamento de Freire, vê-se que houve uma

\footnotetext{
${ }^{10}$ BRASIL. Lei n. 10.639, de 9 de janeiro de 2003. Altera a Lei no 9.394, de 20 de dezembro de 1996, que estabelece as Diretrizes e Bases da Educação Nacional, para incluir no Currículo Oficial da Rede de Ensino a obrigatoriedade da temática "História e Cultura Afro-Brasileira" e dá outras providências.

11 Trecho da fala do presidente da comunidade quilombola, ela foi extraída de entrevista semiestruturada realizada em junho de 2016 para esta pesquisa. Transcrita tal como foi falada.
} 
tentativa de escantilhar a cultura negra da prateleira da importância na formação do povo brasileiro.

$\mathrm{Na}$ atualidade, as lutas de resistência negra fizeram surgir inúmeros questionamentos sobre o ensino de História e o uso do livro didático da comunidade remanescente quilombola, dentre estes podemos destacar: como o livro didático de História do $6^{\circ}$ ano do ensino fundamental II, adotado na comunidade Manga/Iús, no Massapé, situada no município de Batalha-Piauí, na escola pesquisada, aborda a perspectiva atual de ensino para áreas remanescentes quilombolas?

Visando responder a esse e a outros questionamentos, este trabalho apresenta como objetivo geral: analisar o livro didático de história do $6^{\circ}$ ano do ensino fundamental da escola pesquisada, situada na comunidade Iús, no Massapé, situada na cidade de Batalha-PI, enquanto área remanescente quilombola a partir de uma análise freireana. Como objetivos específicos: verificar a concepção de história e o ensino de história que estão implícitos no livro de história do $6^{\circ}$ ano do fundamental II; reconhecer nos conteúdos e abordagens do livro didático de História, as indicações da Lei 10.639/03, que prevê o ensino da História e cultura afro-brasileira em todas as escolas públicas e privadas; e identificar como o livro didático de História reflete as orientações de ensino das diretrizes curriculares nacionais para a educação escolar quilombola na educação básica/2012.

No campo metodológico, este trabalho apresenta-se como uma pesquisa bibliográfica e de campo de caráter qualitativo, sendo que a pesquisa bibliográfica se caracteriza pelo estudo que visa levantar questionamentos e ainda respondê-los, tendo por base a literatura já publicada. Com esse intuito, essa pesquisa se fundamenta em outras pesquisas, livros e artigos já publicados a respeito da temática abordada, dos quais em sua maioria, se apoiam em estudos de autores como: Carril (2017); Munanga e Gomes (2004); Moura (1987); e Freire (1967; 1987), que tratam do ensino de história no Brasil, em especial nas escolas remanescentes quilombolas, e as relações educacionais no caso de Freire.

\section{Material e Metodologia}

Como instrumentos de coleta de dados sobre a escola pesquisada, podemos destacar entrevistas e questionários estruturados, que foram aplicados mediante autorização para divulgação dos participantes dessa pesquisa por meio do Termo de Consentimento Livre e Esclarecido (TCLE). 
A pesquisa está dividida em partes, em que, na primeira relatamos um pouco da situação da população negra no Brasil e das principais conquistas advindas de leis e decretos. Em seguida, abordamos resumidamente a situação do ensino de história e cultura afrobrasileira e africana, para depois descrevermos qual a concepção de ensino e de história na comunidade pesquisada, considerando o pensamento de Paulo Freire. Analisamos o livro utilizado na comunidade, de forma a identificar se atende às especificações propostas nas Diretrizes Curriculares Nacionais para a Educação das Relações Étnico-Raciais e para o ensino de História e Cultura Afro-Brasileira e Africana, e, por fim, debatemos as análises de Freire acerca da educação.

\section{Resultados e Discussão}

Desde os seus primeiros trabalhos, Paulo Freire defendeu a igualdade de educadores e educadoras com educandas e educandos. Nessa perspectiva, Freire planejou uma proposta de educação popular, preocupando-se mais com a história de cada sociedade, de cada cultura e de cada povo, do que com estilo acadêmico.

Conhecer a comunidade de remanescentes de quilombos Manga/Iús de perto foi extremamente importante para que os primeiros olhares despertassem para a necessidade de realizar o trabalho em uma metodologia freireana, haja vista a sua relevância para a educação local, possibilitando, dessa forma, aos estudantes, refletirem sobre suas vivências cotidianas locais, contextualizando e valorizando a cultura que é inerente à condição humana. Por sua vez, respeitando a Lei 10.639/03, sem sobrepô-la as demais, pois, pela Lei de Diretrizes e Bases da Educação e pela Resolução nº 8/2012 do Conselho Nacional de Educação, os quilombolas têm direito à educação diferenciada, na qual deve constar formação de conteúdo e prática pedagógica, além de limites ao fechamento das escolas quilombolas. Trata-se, nesse sentido, de uma atenção diferenciada para as escolas situadas em territórios quilombolas, mas não de ações para uma escola quilombola diferenciada.

Desse modo, a metodologia freireana na educação escolar quilombola é de fundamental importância, uma vez que educar para a igualdade tem como pressuposto uma educação antirracista, garantindo a equidade entre os diversos grupos étnicos raciais, mas para isso depende de inúmeras ações, entre as quais conhecer e trazer para o cotidiano escolar, conteúdos que estimulem a participação de alunos e alunas negras como atores sociais ativos, com a intencionalidade de promover a igualdade de oportunidades e o exercício da cidadania, como prevê a legislação brasileira, que na Resolução CNE nº 01/2004 garante "igual direito 
às histórias e culturas que compõem a nação brasileira, além do direito de acesso às diferentes fontes da cultura nacional a todos brasileiros" (BRASIL, 2004, p. 1).

Entretanto, na escola municipal pesquisada, tal metodologia permanece distante da realidade dos discentes, é notório o uso de metodologias ultrapassadas pelos docentes, a citar, o uso apenas do livro didático, insuficiente até na quantidade.

\title{
Leis que defendem a luta quilombola pela educação
}

\begin{abstract}
Opúnhamo-nos a estas soluções assistencialistas, ao mesmo tempo em que não aceitávamos as demais, porque guardavam em si uma dupla contradição. Em primeiro lugar, contradiziam a vocação natural da pessoa - a de ser sujeito e não objeto, e o assistencialismo faz de quem recebe a assistência um objeto passivo, sem possibilidade de participar do processo de sua própria recuperação. Em segundo lugar, contradiziam o processo de "democratização fundamental" em que estávamos situados. (FREIRE, 1967, p. 56).
\end{abstract}

Paulo Freire (1967) opunha-se a esse assistencialismo ${ }^{12}$, pois ele inferioriza a figura a ser favorecida e glorifica o beneficiário. O que se pode mencionar é que as leis que favoreciam a educação quilombola são de cunho constitucional, um direito a todo cidadão brasileiro de acesso à educação e cultura.

Após anos de luta contra injustiças históricas, sociais e políticas, a Lei $\mathrm{n}^{\mathbf{0}} 10.639$ (BRASIL, 2003b), promulgada em 9 de janeiro de 2003, foi uma conquista do movimento negro brasileiro, ao estabelecer as diretrizes e bases da educação nacional, determinando a inclusão da temática "História e Cultura Afro-brasileira" no currículo oficial da Rede de Ensino.

Em 10 de março de 2008, foi promulgada a Lei $\mathrm{n}^{\circ} 11.645$, que complementou a lei supramencionada, acrescentando a obrigatoriedade do ensino da história e da cultura indígena. O objetivo do estudo da Hhistória e da cultura africana, afro-brasileira e indígena é o combate pedagógico ao racismo por meio da desconstrução do ideário inferiorizado de negros e indígenas construído pela sociedade desde o período escravocrata. Portanto, as leis $10.639 / 2003^{13}$ e $11.645 / 2008^{14}$ não têm por objetivo a mera exposição da história e cultura desses povos, mas a reeducação das relações étnico-raciais.

\footnotetext{
12 Assistencialismo: sistema ou prática de ação social que organiza e oferece assistência às comunidades desfavorecidas e excluídas de uma sociedade, auxiliando e apoiando momentaneamente seus membros ao invés de combater as causas que os deixaram em estado de carência ou de pobreza (Fonte: Dicionário Online de Português).

${ }^{13}$ Lei ${ }^{\circ} 11.645$, de 10 março de 2008. Art. $1^{\circ}$, o art. 26-A da Lei n. 9.394, de 20 de dezembro de 1996, passa a vigorar com a seguinte redação: "Art. 26-A. Nos estabelecimentos de ensino fundamental e de ensino médio,
} 
Para atingir esse objetivo, os educadores devem se guiar pelas Diretrizes Curriculares Nacionais para a Educação das Relações Étnico-Raciais e para o Ensino de História e Cultura Afro-Brasileira e Africana de outubro de 2004, uma vez que elas detalham os conteúdos estabelecidos no art. 26, da Lei ${ }^{\circ} 11.645 / 2008$, assim como dispõem princípios e orientações norteadoras aos professores.

No ano de 2012, mais uma conquista quilombola. Dada a significativa importância social, política e cultural das comunidades quilombolas, a Resolução CNE nº 8/2012 é homologada e definidas as Diretrizes Curriculares Nacionais para a Educação Escolar Quilombola na Educação Básica, na qual se busca uma escola que tenha como pauta a

valorização da memória coletiva, das línguas reminiscentes, dos marcos civilizatórios, das práticas culturais, das tecnologias e formas de produção do trabalho, dos acervos e repertórios orais, dos festejos, usos, tradições e demais elementos que conformam o patrimônio cultural das comunidades quilombolas de todo o país e da territorialidade. (BRASIL, 2012, p. 4-47).

A educação quilombola busca sair de um viés positivista de ensino e trazer uma nova abordagem, mais plural e não conservadora, caracterizando-se como uma educação diferenciada do habitual curricular. Nela, os objetos dos estudos serão as peculiaridades de cada comunidade, frisando-se que a oralidade será a base dessa educação e que a pedagogia e os objetivos respeitarão as especificidades, as crenças e os modos desses indivíduos, tendo-os como o foco de um contexto.

$\mathrm{Na}$ medida em que esta visão "bancária" anula o poder criador dos educandos ou o minimiza, estimulando sua ingenuidade e não sua criticidade satisfaz aos interesses dos opressores: para estes, o fundamental não é o desnudamento do mundo, a sua transformação. (FREIRE, 1987, p. 39).

Nessa perspectiva, sair de uma educação positivista, representa deixar de lado a história dos "vitoriosos", representada pelo homem branco europeu e suas metodologias, e partir para uma educação mais plural. Ressignificando o pensamento de Freire, essa educação bancária vem a ser combatida, pois o aluno e a comunidade têm que se fazerem presentes no ato do ensino; projetos pedagógicos envolvendo toda uma complexidade sociocultural compõem a meta.

públicos e privados, torna-se obrigatório o estudo da história e cultura afro-brasileira e indígena" (BRASIL, 2008).

${ }^{14}$ Art. $1^{\circ}$. A Lei no 10.639, de 9 de janeiro de 2003: “Art. 26-A. Nos estabelecimentos de ensino fundamental e médio, oficiais e particulares, torna-se obrigatório o ensino sobre História e Cultura Afro-Brasileiras" (BRASIL, 2003). 
Segundo Freire (1987, p. 44), “o educador já não é o que apenas educa, mas o que, enquanto educa, é educado, em diálogo com o educando que, ao ser educado, também educa". $\mathrm{O}$ autor defende ainda que, durante o ato de educar, o essencial é que haja trocas de conhecimentos fundamentais. No caso da educação quilombola, essas trocas se dão diante dos alunos, professores e comunidade.

Amilcar Pereira (2016) elenca uma série de fatores que impedem a eficaz implantação do ensino da história e cultura africana e afro-brasileiras nas escolas, entre elas está a falta de profissionais habilitados para lecionar de maneira eficaz, assim como a produção de conhecimentos sobre a temática. O descaso por parte das políticas públicas e dos governantes fazem com que esses projetos de implementações esbarrem em escolas precárias, materiais didáticos escassos e falta de profissionais adequados. ${ }^{15}$

\section{Dificuldades para o ensino quilombola}

Paulo Freire (1967) parte de um preceito em defesa de uma educação que coloque nos mesmos degraus os pensamentos de diferentes indivíduos, em distintos espaços socioculturais e em diálogo com diferentes períodos. A educação com um caráter mediador histórico e de equidade social.

Seja na rede pública ou privada, o ensino de História africana e afro-brasileira deve estar presente como disciplina obrigatória nos currículos do Ensino Fundamental e Médio, conquista essa, adquirida com a implantação da Lei 10.639/2003, que logo foi alterada pela Lei 11.645/2008, que torna obrigatório o ensino da história e cultura afro-brasileira e africana em escolas públicas e privadas, tanto no ensino fundamental quanto no ensino médio, e propõe novas diretrizes para o ensino de história no país.

A partir da educação, segundo Freire (1967), será possível uma discussão plausível sobre suas problemáticas e os anseios na qual a comunidade que habita está necessitando, haja vista que o modelo educacional pensado por Freire busca sempre uma educação libertadora ${ }^{16}$, na qual o estímulo ao senso crítico e transformador de um contexto social é a principal pauta congruente, visando um aperfeiçoamento da educação brasileira.

\footnotetext{
${ }^{15}$ Educação Escolar na Comunidade Quilombola Contente. As autoras, ao longo da obra, vão explanar acerca do projeto pedagógico com base nas diretrizes da educação, entre as quais pode-se destacar a Lei 10.639/2003, onde as autoras buscam formular uma crítica construtiva no tocante a importância para a educação quilombola na busca para que haja um desenvolvimento maior da educação quilombola (SILVA; LEITE (2020).

${ }^{16}$ FREIRE, P. Educação como Prática Libertadora. Rio de Janeiro: Paz e Terra, 1967.
} 
Na comunidade Manga/Iús, foram observadas dificuldades "corriqueiras" das escolas quilombolas do Brasil, dificuldades como a infraestrutura da escola comunitária que se apresentam com somente quatro salas em um prédio deteriorado, sem computadores para uso administrativo ou dos discentes, e sem funcionar o ano letivo completo graças a má infraestrutura das estradas adjacentes a escola. Empecilhos esses que dificultam esse debate trazido por Freire.

Quanto ao acesso à escola, somente no período de estiagem chuvosa os alunos têm acesso, pois no período chuvoso o acesso fica inviável devido à falta de infraestrutura das estradas, que se tornam intrafegáveis, e só funciona no segundo semestre no período regulamentar. Todavia, devido à pandemia da Covid-19, em virtude de as aulas serem ofertadas de modo Online, o calendário acadêmico se fez o ano todo.

Quanto ao cardápio alimentar ${ }^{17}$, não há o específico, ou pelo menos um que a Secretaria de Educação procure adequar de acordo com as possibilidades. O calendário escolar não privilegia as práticas, tradições e datas comemorativas da comunidade. A formação continuada dos professores não ocorre de forma específica e a comunidade não participa da elaboração do Projeto Político Pedagógico ${ }^{18}$. A falta de livros didáticos específicos para a implementação do ensino de História se faz presente, tendo em vista a necessidade de utilização de livros específicos de História para a comunidade, que traria à tona como necessária essa valorização cultural da comunidade.

A questão da escassez de materiais adequados é uma atenuante considerável, haja vista a necessidade de um aparato legal de materiais didáticos diferenciados, conforme dispõe o Ministério da Educação em normas sobre questões fundamentais para a educação quilombola.

Considerando o que consta no art. 205 da Constituição de 1988 - "A educação, direito de todos e dever do Estado e da Família, será promovida e incentivada com a colaboração da sociedade, visando ao pleno desenvolvimento da pessoa, seu preparo para o exercício da cidadania e suas qualificações para o trabalho" (BRASIL, 1988, p. 34) - verificamos que a Carta Magna exprime, com muita clareza, vontade de assegurar a educação a todos por direito, porém, a falta de incentivos financeiros constantes faz com que seja notado um "abismo" entre a educação pública e a particular, em especial nas escolas comunitárias, nas quais essas precariedades são mais vigentes. Atenuantes plausíveis para se afirmar que a

\footnotetext{
${ }^{17}$ Resolução no 8/2012. Assegurar que a alimentação e a infraestrutura escolar quilombola respeitem a cultura alimentar do grupo, observando o cuidado com o meio ambiente e a geografia local (BRASIL, 2012).

${ }^{18}$ Resolução $n^{\circ}$ 8/2012. Promover a formação específica e diferenciada (inicial e continuada) aos/às profissionais das escolas quilombolas, propiciando a elaboração de materiais didático-pedagógicos contextualizados com a identidade étnico-racial do grupo (BRASIL, 2012).
} 
educação pensada por Freire não se concretizou, uma vez que, questões como o estímulo ao senso crítico dos discentes, evasiva de uma sala de aula unilateral e vertical onde o professor é o detentor do conhecimento e o aluno tem uma participação mínima, e fugir de uma educação bancária $^{19}$, na qual o discente é indeferido de pensar além do que lhe é exposto. No entanto, a falta de infraestrutura e tecnologias mínimas e a escassez de livros adequados, não propiciaram e deterioraram o pensar de fazer uma educação freireana na devida comunidade.

Miranda (2012, p. 374-375) faz um perfil das escolas quilombolas:

Em nível nacional, o censo escolar constata que os piores indicadores educacionais se referem a essas escolas: são pequenas, em geral possuindo duas salas que funcionam em regime multisseriado. A maioria das construções é de pau a pique. Faltam energia elétrica, água encanada e saneamento básico.

É notório que, na maioria dos casos, a comunidade quilombola ou os alunos não fazem parte dos planejamentos das atividades desenvolvidas nas escolas, a citar o projeto político pedagógico, ferramenta de relevante importância. O descaso por parte do poder público, penaliza a escola pesquisada, na comunidade Manga/Iús, a não oferecer o mínimo necessário para se fazer a educação segundo os critérios instituídos por lei.

Quanto aos professores, seguindo critérios adotados pelo Ministério da Educação, a questão dos profissionais de educação é de fundamental importância para se fazer a educação quilombola próspera. Os estudantes, os professores e a comunidade têm que estar em sincronia na busca por aprender, ensinar e perpetuar a cultura e tradições das comunidades. Vale ressaltar os serviços de apoio $^{20}$ para os profissionais da educação, auxiliando nas aulas a partir de um segundo professor, membro da comunidade, que irá ajudar o professor durante o ensino acerca das peculiaridades de cada comunidade.

Vale salientar que a admissão de profissionais da educação para atuar nas comunidades quilombolas se dá a partir da realização de concurso público. Uma educação de qualidade, segundo Paulo Freire, é uma educação para a liberdade. Ou seja, uma educação libertadora do opressor, haja vista que esse opressor se faz através de dominações, trazendo

\footnotetext{
${ }^{19}$ FREIRE, P. Pedagogia do Oprimido. 8. ed. Rio de Janeiro: Paz e Terra, 1980.

${ }^{20}$ Resolução $n^{\circ}$ 8/2012. Define Diretrizes Curriculares Nacionais para a Educação Escolar Quilombola na Educação Básica. Art. 13. Recomenda-se que os sistemas de ensino e suas escolas contratem profissionais de apoio escolar oriundos das comunidades quilombolas para produção da alimentação escolar, de acordo com a cultura e os hábitos alimentares das próprias comunidades. Parágrafo único, os sistemas de ensino em regime de colaboração poderão criar programas de Educação Profissional Técnica de Nível Médio para profissionais que executam serviços de apoio escolar na Educação Escolar Quilombola, de acordo com o disposto na Resolução CNE/CEB n. 5/2005, fundamentada no Parecer CNE/CEB 16/2005, que cria a área Profissional n. 21, referente aos Serviços de Apoio Escolar. (BRASIL, 2012).
} 
para o contexto da sala de aula, o professor é superior ao aluno. No entanto, o que a educação quilombola busca é justamente esse diferencial, ou seja, uma educação pautada em práticas populares, oralidade, diversidade e comunidade.

A ausência de profissionais capacitados é um grave problema, pois interfere de maneira significativa no ensino:

A maioria dos professores não é capacitada adequadamente, e o número é insuficiente para atender à demanda. Em muitos casos, uma professora ministra aulas para turmas multisseriadas. Poucas comunidades têm unidade educacional com o ensino fundamental completo. (BRASIL, 2018).

Questões como um único professor ministrar aulas para turmas multisseriadas, com alunos de diferentes idades e séries, dificultam a implementação. Os poucos recursos destinados pelos governos vigentes ao ensino em específico, corroboram para as objeções na aprendizagem e da formação dos discentes, interferindo, por sua vez, nos estudos e na continuidade do ensino. Na comunidade Manga/Iús, pode-se observar a falta de professores formados em história, contendo ao todo um corpo docente de cinco profissionais da educação, todos formados em Pedagogia, a falta de um profissional formado em história, de materiais didáticos especializados e de um segundo tutor, membro da comunidade, auxiliando o trabalho do professor titular, é uma questão presente na comunidade.

A escassez de recursos destinados às comunidades para sanar problemas estruturais das escolas acarretam de maneira acentuada na precariedade do cenário educacional, uma vez que os alunos não têm sequer o conforto minimamente necessário nas salas de aula e no esqueleto escolar. Conforme dispõe o Ministério da Educação, é necessário construir um planejamento pedagógico que respeite e unifique a cultura e os membros da comunidade quilombola à qual a criança faz parte. Além disso, o sistema deve assegurar uma infraestrutura capaz de abarcar as necessidades desses grupos, a exemplo de transportes escolares e prédios adequados (BRASIL, 2012).

Freire pensa uma educação na qual se busca a liberdade e a democratização do Brasil, apregoando uma equidade entre as diferentes classes sociais, independentemente de cor de pele, status social, religião ou região habitada:

Pensávamos numa alfabetização direta e realmente ligada à democratização da cultura, que fosse uma introdução a esta democratização. Numa alfabetização que, por isso mesmo, tivesse no homem, não esse paciente do processo, cuja virtude única é ter mesmo paciência para suportar o abismo 
entre sua experiência existencial e o conteúdo que lhe oferecem para sua aprendizagem, mas o seu sujeito. (FREIRE, 1967, p. 104).

Os impasses observados na escola lócus da pesquisa são problemas frequentes, observados em tantas outras escolas comunitárias do Brasil. Esses atenuantes corroboram de maneira significativa em dificultar a implementação quilombola seguindo o modelo educacional proposto por Freire, ou seja, a educação libertadora pregada por ele se apresentando de maneira exígua na comunidade. Questões mínimas como infraestrutura ou materiais didáticos, que seriam fundamentais para que houvesse uma alfabetização democrática, corroboram para o distanciamento de uma efetiva educação libertadora.

\section{O livro didático adotado na comunidade Manga/Iús}

A precariedade e a falta de assistência que essas escolas apresentam, somadas à falta de profissionais adequados, dificultam de maneira significativa a implementação desse ensino diferenciado. A intolerância, a xenofobia e o racismo se fizeram presente ao longo de séculos de luta quilombola, que além de resistir a esses preconceitos, tem que conviver com um protecionismo do estado, o qual deixa esses grupos "sufocados" em todas as circunstâncias.

A implementação da educação quilombola busca ressignificar o conceito de educação, tendo em vista que o modelo educacional brasileiro apresenta um viés positivista, no qual prioriza a "história dos vitoriosos", ou seja, o homem branco, da elite e europeu. Freire defende uma educação "parecida com a nossa realidade" (FREIRE, 1967, p. 106). Tendo por base o pensamento do autor, a importância de um livro didático próprio é ratificada. $\mathrm{O}$ ato de o discente ler o material escolar e se sentir representado e encaixado dentro da literatura e cultura abordadas no material didático é de primazia na busca pela autenticação e perpetuação cultural da comunidade referida. Uma educação libertadora, no entanto, não é uma realidade que se faz presente na escola comunitária aqui abordada.

Em entrevista com o professor Antônio Barroso Neto, visando compreender as dificuldades existentes para o ensino de história e cultura afro-brasileira e indígena na referida comunidade quilombola, foram indagados alguns pontos, a citar: a sua formação acadêmica; o material adotado para o ensino da referida matéria; a existência de livros para todos os alunos; e o seu tempo de trabalho na escola.

Inicialmente, salienta-se que a escola oferta os seguintes níveis de ensino: Creche $1 \mathrm{e}$ 2, Pré-escola 1 e 2 e Ensino Fundamental nos níveis I e II. O professor de História, Antônio Barroso Neto, que é o responsável pela disciplina de História em todos os níveis de ensino na 
referida instituição, não possui formação na área, sendo graduado em Pedagogia com especialização em Gestão e Supervisão Escolar. Com a pesquisa constatou-se que o professor iniciou suas atividades educacionais naquela escola no corrente ano, razão pela qual é possível depreender a inexistência de uma formação continuada pelos alunos.

O livro adotado pela Educação Municipal de Batalha é de autoria de Gilberto Cotrim, e foi adotado por todas as escolas do município. O material didático aborda em sua composição a história a partir do ponto de vista do homem branco, tornando invisíveis as demais populações, como as negras e indígenas. Invisibilidade essa que faz com que os povos não representados sejam inferiorizados em suas páginas, e cria e reforça diversos estereótipos, levando à negação de seus valores culturais, o que consequentemente acaba por dar preferência aos grupos sociais de culturas exaltadas como superiores. Outro ponto é a ausência de material didático para todos os alunos, contribuindo assim, para a ineficácia da educação, da cultura e da história afro-brasileira e indígena na referida comunidade.

\section{Importância da educação quilombola "freireana"}

Paulo Freire (1967), com clareza, defende a ideia da "educação como liberdade". No entanto, o observado perante o estudo realizado é que a infraestrutura precária da escola lócus da pesquisa, associada à escassez de materiais didáticos fundamentais e diferenciados, uma participação mais ativa da comunidade, a falta de profissionais formados em História e especializados na educação quilombola, são desafios que fazem a educação na comunidade não estar caracterizada no quadro de "libertadora" no sentido atribuído por Freire.

No ano de 2010, o Brasil sediou o Primeiro Seminário de Educação Quilombola, em Brasília, no qual visava projetar um plano Nacional de Educação Quilombola, contando com a participação de professores e lideranças quilombolas. No ano de 2012, a Resolução n ${ }^{\circ}$ 8/2012, que define diretrizes curriculares nacionais para a educação escolar quilombola na educação básica, foram de fundamental importância para a educação quilombola, e ressalta diversas resoluções como a Resolução CNE/CP n $1 / 2004$, que define Diretrizes Curriculares Nacionais para a Educação das Relações Étnico-Raciais e para o Ensino de História e Cultura Afro-brasileira e Africana (BRASIL, 2012, p. 2).

A Resolução $n^{\circ}$ 8/2012 busca, de maneira democrática, viabilizar a educação para um número maior de indivíduos, chegando em todas as escolas do Brasil, contribuindo para o desenvolvimento crescente das comunidades quilombolas, primando por uma participação 
efetiva e maior da comunidade em vários aspectos étnico-culturais e a implementação do ensino de História como mecanismo de superação a preconceitos e discriminações raciais.

A notoriedade da educação quilombola e a implementação do ensino de uma História diferenciada, se fazem presentes no âmbito sociocultural, buscando a valorização de traços e tradições culturais, respeito aos territórios, à memória, à ancestralidade, e aos conhecimentos tradicionais, sem deixar de lado a participação das lideranças comunitárias, conforme previsto na convenção de 169 da Organização Internacional do Trabalho (OIT). ${ }^{21}$ Dessa forma,

Esse modelo diferenciado de educação escolar se centraliza na realidade das comunidades quilombolas, valoriza a territorialidade como espaço educativo, estabelece contatos respeitosos com valores ancestrais cultuados pela comunidade: a oralidade; a religião de matriz africana e demais questões vinculadas à população afro-brasileira; o combate ao racismo, às desigualdades raciais, que, segundo a Organização das Nações Unidas ONU -, são as principais fontes geradoras das desigualdades sociais. (ROCHA; SILVA, 2021, p. 82).

\section{Considerações finais}

A educação quilombola é um dos principais símbolos das conquistas da resistência negra no Brasil. Como pregado por Paulo Freire, uma educação que viria a democratizar uma sociedade no sentido de oportunizar um espaço para todos os grupos sociais; emergindo-os, dando-lhes espaço de fala e reflexão dentro da sociedade. A Educação como porta de acesso a tais garantias, visto que ela se caracteriza como um dos instrumentos responsáveis por transmitir o legado das lutas das gerações anteriores aos mais jovens através da valorização cultural, como previsto nas Diretrizes Curriculares Nacionais para a Educação Escolar Quilombola na Educação Básica de 2012.

"Visando a educação e a transformação das relações étnico-raciais e criando pedagogias de combate ao racismo e às discriminações, o caminho escolhido pelas Diretrizes foi a valorização da história e da cultura negra" (BRASIL, 2004, p. 9). Sendo assim, é preciso chamar a atenção para a importância dos conceitos de cultura e identidade negras e/ou afrobrasileiras.

Como afirmam as Diretrizes, o reconhecimento exige justiça e igualdade de direitos sociais, civis, econômicos e culturais, assim como "a adoção de políticas educacionais e de estratégias pedagógicas que valorizem a diversidade, visando superar as desigualdades étnico-

\footnotetext{
${ }^{21}$ Convenção $n^{\circ} 169$ da Organização Internacional do Trabalho sobre povos indígenas e tribais em estados independentes.
} 
raciais presentes na educação escolar brasileira, nos diferentes níveis de ensino" (BRASIL, 2004, p. 12).

Nesse sentido, a reeducação trará uma nova perspectiva do que é fazer história e educar uma comunidade ensinando a partir de preceitos nos quais o positivismo, tão presente na educação brasileira convencional, é deixado de lado, e o foco da questão será essa minoria que tanto anseia por seu reconhecimento, ganhando mais espaço de fala, pensamentos e mostrando a relevância da cultura negra no berço da educação brasileira, que é a escola. Uma educação que emerja e dê voz e vez para essas populações, desatrelando das amarras do estado e de um assistencialismo opressor. Freire (1987, p. 20) destaca:

A grande generosidade está em lutar para que, cada vez mais, estas mãos, sejam de homens ou de povos, se estendam menos, em gestos de súplica. Súplica de humildes a poderosos. E se vão fazendo, cada vez mais, mãos humanas, que trabalhem e transformem o mundo.

Com a implementação da educação quilombola, busca-se trazer uma nova perspectiva do fazer história e de modelo educacional, trazendo um novo panorama desde uma história mais voltada à oralidade, até outra vista quanto a costumes, tradições e crenças dessas ricas histórias afro no território brasileiro. Após o estudo realizado com a Comunidade Manga/Iús na zona rural de Batalha/PI, verificou-se a ausência na prática da educação escolar quilombola, que é exigida por lei.

A citar, a falta de professores com formação específica, o que dificulta aos alunos advindos das comunidades remanescentes de quilombos acesso à educação que corresponda ao conhecimento, à valorização e à prática de sua cultura e saberes. A falta de estrutura na referida escola é outro ponto que chama atenção. Como a região é de difícil acesso, uma vez que ela se localiza no Massapé, os alunos frequentam a unidade escolar apenas no mês de julho, ou seja, eles têm aulas somente no segundo semestre de cada ano. Os gestores alegam que, na localidade Manga/Iús, as aulas ocorrem dessa forma em razão das fortes chuvas no período do inverno, que tornam as estradas intrafegáveis. Dessa forma, quanto ao calendário, ele "deve incluir as datas consideradas mais significativas para a população negra e para cada comunidade quilombola, de acordo com a região e a localidade, consultadas as comunidades e lideranças quilombolas" (BRASIL, 2012 p. 7).

Conforme dito mais acima, não há um calendário em específico ou, pelo menos, um que a Secretaria de Educação procure adequar de acordo com as possibilidades. $\mathrm{O}$ calendário escolar não privilegia as práticas, as tradições e as datas comemorativas da comunidade. A 
formação continuada dos professores não ocorre de forma específica e a comunidade não participa da elaboração do Projeto Político Pedagógico.

A democratização do Brasil a partir da educação defendida por Freire, levando em consideração as problemáticas aqui apresentadas, faz-se imaginar um cenário utópico. As enormes deficiências estruturais e educacionais enfrentadas pela escola pesquisada levam a crer que há muito a ser mudado e melhorado por parte dos governantes para melhor conforto dos alunos, dos professores e da comunidade.

Há muitas lacunas a serem preenchidas, as diretrizes apontadas pela Lei por si só não dão conta de tamanha demanda se não houver um esforço mútuo entre Governo Federal, estadual e municipal, e, na ponta do processo, pessoas intimamente ligadas e empenhadas com uma educação justa e igualitária. A educação quilombola, portanto, torna-se eficiente e necessária a seu povo na medida em que suas condições estruturais e pedagógicas possam proporcionar uma prática educacional condizente com aquilo que é previsto em lei.

O reconhecimento ainda exige o questionamento das visões sobre relações raciais no Brasil, assim como a valorização e o respeito à história da resistência negra e da cultura dos africanos e seus descendentes. Nesse sentido, a reeducação trará uma nova perspectiva do que é fazer história e educar uma comunidade, ensinando a partir de preceitos nos quais o positivismo, tão presente na educação brasileira convencional, é deixado de lado e o foco da questão se volta para as classes subalternas, que tanto anseiam pelos seus reconhecimentos, ganhando uma notoriedade e espaço de fala e pensamentos, assim como mostrando a relevância da cultura negra no berço da educação brasileira que é a escola.

É necessário refletir sobre todas essas nuances, caso contrário não haverá mudanças e provavelmente o ensino da história e da cultura das comunidades quilombolas permanecerão na invisibilidade e certamente perecerão. Uma perda que será sentida de forma nacional, por tais comunidades abrigarem em seu seio grande parte da história do Brasil. Trata-se de mostrar a importância das leis que asseguram direitos necessários básicos para a perpetuação da luta pela educação quilombola travada por representantes dos movimentos negros.

\section{Referências}

BRASIL. [Constituição (1988)]. Constituição da República Federativa do Brasil de 1988. Brasília, DF: Senado Federal, 1988. Disponível em: http://www.planalto.gov.br/ccivil_03/constituicao/constituicao.htm. Acesso em: 15 maio 2021. 
BRASIL. Decreto $\mathrm{n}^{\mathbf{0}} \mathbf{4 . 8 8 7}$, de 20 de novembro de 2003. Regulamenta o procedimento para identificação, reconhecimento, delimitação, demarcação e titulação das terras ocupadas por remanescentes das comunidades dos quilombos de que trata o art. 68 do ato das disposições constitucionais transitórias. Brasília, DF, 2003a. Disponível em:

https://www.planalto.gov.br/ccivil_03/decreto/2003/d4887.htm. Acesso em: 20 mar. 2021.

BRASIL. Ministério da Educação. Educação Quilombola: Apresentação Disponível em: http://portal.mec.gov.br/educação-quilombola. Acesso em: 23 mar. 2021.

BRASIL. Lei $\mathbf{n}^{\mathbf{0}}$ 10.639, de 9 de janeiro de 2003. Altera a Lei n. 9.394, de 20 de dezembro de 1996, que estabelece as Diretrizes e Bases da Educação Nacional para incluir no Currículo Oficial da Rede de Ensino a obrigatoriedade da temática "História e Cultura Afro-Brasileira" e dá outras providências. Brasília, DF, 2003b. Disponível em: http://www.planalto.gov.br/ccivil_03/leis/2003/110.639.htm\#: :text=LEI\%20No\%2010.639\% 2C\%20DE\% 209\%20DE\%20JANEIRO\%20DE\%202003.\&text=Altera\%20a\%20Lei\%20no,\% $22 \% 2 \mathrm{C} \% 20 \mathrm{e} \% 20 \mathrm{~d} \% \mathrm{C} 3 \% \mathrm{~A} 1 \% 20$ outras\%20provid\%C3\%AAncias. Acesso em: 20 mar. 2021.

BRASIL. Lei $\mathbf{n}^{\mathbf{0}}$ 11.645, de 10 de março de 2008. Altera a Lei $\mathrm{n}^{\circ} 9.394$, de 20 de dezembro de 1996, modificada pela Lei n. 10.639, de 9 de janeiro de 2003, que estabelece as Diretrizes e Bases da Educação Nacional para incluir no currículo oficial da rede de ensino a obrigatoriedade da temática "História e Cultura Afro-Brasileira e Indígena". Brasília, DF, 2008. Disponível em: http://www.planalto.gov.br/ccivil_03/_ato20072010/2008/lei/111645.htm. Acesso em: 21 jan. 2021.

BRASIL. Resolução no 1, de 17 de junho de 2004. Diretrizes Curriculares Nacionais para a Educação das Relações Étnico-Raciais e para o Ensino de História e Cultura Afro-Brasileira e Africana. Brasília, DF, 2004. Disponível em:

http://portal.mec.gov.br/dmdocuments/cnecp_003.pdf. Acesso em: 20 mar. 2021.

BRASIL. Resolução no 8, de 20 de novembro de 2012. Define as Diretrizes Curriculares Nacionais para a educação escolar quilombola na educação básica. Brasília, DF, 2012. Disponível em:

http://portal.mec.gov.br/index.php?option=com_docman\&view=download\&alias=11963rceb008-12-pdf\&category_slug=novembro-2012-pdf\&Itemid=30192. Acesso em: 10 jul. 2021.

CARRIL, L. de F. B. Os desafios da educação quilombola no Brasil: o território como contexto e texto. Rev. Bras. Educ, Rio de Janeiro, v. 22, n. 69, p. 539-564, abr./jun. 2017. Doi: 10.1590/S1413-24782017226927. Disponível em: https://www.scielo.br/j/rbedu/a/L9vwgCcgBY6sF4KwMpdYcfK/?lang=pt. Acesso em: 2 jul. 2021.

SILVA, F. das C. da ; LEITE, M. J. dos S. Educação escolar na Comunidade Quilombola Contente. Curitiba: Appris, 2020.

FREIRE, P. A pedagogia do oprimido. 17. ed. Paz e Terra. Rio de Janeiro, 1987.

FREIRE, P. Educação como prática da liberdade. Paz e Terra. Rio de Janeiro, 1967. 
MIRANDA, S. A.de. Educação escolar quilombola em Minas Gerais: entre ausências e emergências. Revista Brasileira de Educação, Rio de Janeiro, v. 17, n. 50, p. 369-498, maio/ago. 2012. Doi: 10.1590/S1413-24782012000200007. Disponível em:

https://www.scielo.br/j/rbedu/a/vtvxW4PdPS4DjskgsjXqxHN/?lang=pt. Acesso em: 30 jun. 2021.

MOURA, C. Quilombos: resistência ao escravismo. São Paulo: Ática, 1987.

MUNANGA, K.; GOMES, N. L. Para entender o negro no Brasil de hoje: história, realidades, problemas e caminhos. São Paulo: Global: Ação Educativa Assessoria, Pesquisa e Informação, 2004.

PEREIRA, A. A. O Movimento Negro Brasileiro e a Lei n ${ }^{\circ}$ 10.639/2003: da criação aos desafios para a implementação. Revista Contemporânea de Educação, Rio de Janeiro, v. 11, n. 22, p. 13-30, jan./abr. 2016. Doi: 10.20500/rce.v12i23.3452. Disponível em: https://revistas.ufrj.br/index.php/rce/article/view/3452. Acesso em: 15 jun. 2021.

ROCHA, M. S. da; SILVA, J. B. da. Reflexões sobre educação escolar quilombola. Teoria \& Prática, Campinas, São Paulo, v. 34, n. 68, p. 79-91, dez. 2016. Doi: 10.34112/23170972a2016v34n68p79-91. Disponível em: https://tp.emnuvens.com.br/ltp/article/view/534. Acesso em: 12 jun. 2021.

Submetido em 4 de julho de 2021. Aprovado em 15 de agosto de 2021. 